notable feature, with vasodilation, oedema, and slightly raised temperature and sweating in the early stages. After a few weeks cold cyanosis develops. The skin is smooth and shiny, and in longstanding, severe cases the soft tissues and sweat glands atrophy.

Sudeck ${ }^{3}$ described the osteoporosis that occurs in all but the mildest cases and may become obvious within a few days. Generalised loss of bone density may be seen in the affected region, but the more distinctive radiological appearance of small, usually rounded, areas of increased translucency, measuring up to $10 \mathrm{~mm}$ in diameter, may be superimposed.

The cause of algodystrophy remains an enigma. Most cases occur after trauma, and an attempt to secure compensation is often thought relevant. The same syndrome may, however, develop after myocardial infarction, herpes zoster, hemiplegia, or barbiturate treatment. The condition has been linked with causalgia and attributed to an excessive outflow of sympathetic nervous discharges from the dorsal horn of the spinal cord. Normal inhibition is lost by interference with the inflow of afferent stimuli along the thickly medullated nerve fibres from peripheral mechanoreceptors. This theory provides an explanation for the efficacy of repeated intensive exercise and the use of vibrators and cooling sprays-and it also explains why sympathetic ganglion blocks, ${ }^{4}$ sympathectomy, and guanethidine infusions ${ }^{5}$ have all been successful in treatment. Betablocking agents by mouth give poorer results.

Corticosteroids have been used empirically, both systemically $^{6}$ and locally, ${ }^{7}$ with some success, and recently calcitonin ${ }^{8}$ has been used enthusiastically in France, where controlled trials are now in progress. We need further scientific studies and controlled trials of treatments, but the first step if we are to make progress is to recognise the disorder earlier and more widely.

\footnotetext{
${ }^{1}$ Schiano, A, Eisinger, J, and Acquaviva, P C, Les Algodystrophies. Paris, Laboratoires Armour Montagu, 1976.

2 Leriche, R, and Fontaine, R, Presse Médicale, 1930, 37, 617.

${ }^{3}$ Sudeck, P, Deutsche Medizinische Wochenschrift, 1902, 28, 336.

4 Steinbrocker, O, Archives of Physical Medicine, 1968, 49, 388.

5 Hannington-Kiff, J G, Lancet, 1977, 1, 1132.

${ }^{6}$ Glick, E N, Rheumatology and Rehabilitation, 1973, 12, 84.

${ }^{7}$ Manfredi, L, Giornale di Medicina Militare, 1965, 115, 89.

${ }^{8}$ Schiano, A, and Acquaviva, P C, Marseille-Médical, 1976, 113, 93.
}

\section{Drug treatment of chronic stable angina pectoris}

Beta-adrenoceptor-blocking drugs now occupy the prime place in the management of patients with chronic stable angina pectoris. They reduce the frequency and severity of anginal attacks, lessen consumption of glyceryl trinitrate, ameliorate electrocardiographic ST segment depression, and improve exercise tolerance. ${ }^{1}$

The beta-blocking drugs in current use are relatively free from major side effects-provided the contraindications are observed; they should be used with caution in patients with heart failure, heart block, severe mitral and aortic valvular disease, peripheral vascular disease, or obstructive airways disease. Furthermore, these drugs should not be withdrawn rapidly from patients with angina, since in some cases this provokes a rebound increase in the frequency and severity of the pain. ${ }^{2}$ Obstructive airways disease and heart failure are not absolute contraindications. Cardioselective beta-blockers (such as metoprolol and atenolol) may be tried under close supervision in patients with obstructive airways disease, and digitalis has been used to advantage with beta-blockers in patients with angina and abnormal left ventricular function. ${ }^{3}$ Some patients, however, with severe stable angina pectoris cannot be prescribed beta-blockers because these are either ineffective or ruled out by coexistent disease. What alternatives are there?

A short-acting nitrite such as glyceryl trinitrate will usually have been the first drug used, and indeed is still one of the most effective drugs for symptomatic relief of angina. Taken sublingually its onset of action is rapid, but the effect lasts only 20-30 minutes. Glyceryl trinitrate does not appreciably dilate diseased coronary vessels ${ }^{4}$; it reduces venous return and there- $\vec{\circ}$ fore ventricular stroke output, so that the systolic pressure falls and left ventricular work decreases. Unfortunately in $\omega^{\prime}$ the frequent doses needed for severe angina glyceryl trinitrate causes flushing, headache, and postural hypotension-side effects that set the limit to the tolerable dose.

The value of long-acting nitrites such as pentaerythritol tetranitrate and isosorbide dinitrate in the treatment of angina is still strongly debated..$^{5-8}$ Taken by mouth in the doses $N$ currently used these drugs show no consistent beneficial 옥 effects ${ }^{9}$-and perhaps this is not surprising, since nitrites $N$ are metabolised rapidly in the liver, so that little active drug $T$ reaches the systemic circulation. ${ }^{10}$ Higher doses might prove more effective ${ }^{11} ; 2 \%$ nitroglycerin ointment, however, has been shown ${ }^{12} 13$ to increase exercise capacity for as long as five hours after a single application to the skin of the chest or $\vec{\theta}$ forearm (as a ribbon of ointment covered with an occlusive 9 dressing).

Prenylamine, dipyridamole, and vitamin $\mathrm{E}$ have been advocated as antianginal agents, but studies have generally shown them to be no more effective than placebo. ${ }^{814-16}$ New drug preparations for the treatment of angina invariably have a strong placebo effect, and double-blind trials are $\bar{c}$ essential for their evaluation.

Such trials have shown that perhexilene maleate reduces the frequency and severity of anginal attacks, and it does not appear to precipitate heart failure or airways obstruction..$^{18}$ It reduces exercise-induced tachycardia in man, but, unlike beta-blockers, it has no effect on the resting heart rate. ${ }^{19} \frac{}{3}$. Perhexilene has been shown to produce coronary and systemic vasodilatation in animals and to reduce left ventricular work 3 and to decrease myocardial oxygen consumption. ${ }^{20}$ Minor side effects such as dizziness, nausea, headaches, and im- N potence seem to be common during the first month of treatment, ${ }^{18}$ and prolonged treatment can cause dose-related abnormalities in liver function tests, though these are usually reversible on stopping treatment. ${ }^{21}$ Overt hepatotoxicity is N fortunately rare. Polyneuropathy ${ }^{22}$ and raised intracranial $\sigma$ pressure $^{23}$ have also occurred in several patients on long-term treatment but again have proved reversible. A proximal myo- $\frac{\bar{D}}{\Phi}$ pathy ${ }^{24}$ has been reported in one patient. Clearly the ratio $\stackrel{?}{+}$ of benefit to risk has to be calculated carefully before this effective antianginal drug is prescribed for long-term use.

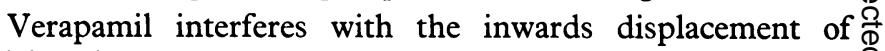
calcium ions across cardiac cell membranes, decreases cardiac $\frac{\varrho}{\sigma}$ contractility, decreases the oxygen requirements of the heart, and does not block beta-adrenoceptors. ${ }^{25}$ Its effectiveness in 8 the treatment of angina is still a matter of debate. ${ }^{26-31}$ It may precipitate heart failure and cause hypotension at high doses and should not therefore be used in conjunction with betablockers. ${ }^{32}$

Within the last few months another calcium antagonist, 
nifedipine, has been introduced as a more potent peripheral and coronary vasodilator than verapamil. It increases coronary blood flow and decreases myocardial oxygen consumption in animals. $^{33}$ Like verapamil and the beta-blockers it has a negative inotropic effect and may therefore theoretically precipitate heart failure, though this has not been observed in clinical studies so far. Minor side effects associated with vasodilatation, such as flushing and headaches, and gastrointestinal intolerance have been reported; no major side effects are evident.

After several quiet years there is now considerable new activity in the treatment of angina. The most difficult question facing the practitioner is what to do with the patient who cannot tolerate beta-blocking drugs because of obstructive airways disease, heart failure, or peripheral vascular disease. On pharmacological grounds, nifedipine, verapamil, and perhexilene seem worth considering; but whether they can win their therapeutic spurs will depend on their clinical performance.

1 Prichard, B N C, Drugs, 1974, 7, 55.

2 Miller, R R, Olson, H G, and Amsterdam, E A, New England fournal of Medicine, 1975, 293, 416.

3 Lancet, 1975, 2, 1136.

4 Oakley, C, British Fournal of Hospital Medicine, 1973, 9, 367.

${ }^{5}$ Goldstein, R E, et al, Circulation, 1971, 43, 629.

6 Logue, R B, and Robinson, P H, Circulation, 1972, 46, 1132.

7 Kay, H B, Drugs, 1977, 13, 276.

${ }^{8}$ Drug and Therapeutics Bulletin, 1974, 12, 1.

${ }^{9}$ Aronow, W S, in Handbook of Experimental Pharmacology, ed P Needleman, p 163. Berlin, Springer-Verlog, 1975.

10 Needleman, P, Lang, S, and Johnson, E M, jun, fournal of Pharmacology and Experimental Therapeutics, 1972, 181, 489.

11 Shane, S J, Canudian Medical Association fournal, 1975, 113, 360.

12 Reichek, N, et al, Circulation, 1974, 50, 348.

${ }^{13}$ Lancet, 1976, 2, 1287.

14 Aronow, W S, American Heart fournal, 1973, 85, 132.

15 Gillilan, R E, Mondell, B, and Warbasse, J R, American Heart fournal, 1977, 93, 444

${ }^{16}$ Anderson, T W, Canadian Medical Association fournal, 1974, 110, 401.

17 Cole, S L, Kaye, H, and Griffith, G C, Circulation, 1957, 15, 405.

${ }^{18}$ Drug and Therapeutics Bulletin, 1976, 14, 97.

${ }^{19}$ Pepine, C J, et al, Postgraduate Medical fournal, 1973, 49, suppl 3, 43.

${ }^{20}$ Hudak, W J, et al, Postgraduate Medical fournal, 1973, 49, suppl 3, 16.

${ }^{21}$ Howard, D J, and Russell Rees, J, British Medical fournal, 1976, 1, 133.

22 Lhermitte, F, et al, British Medical fournal, 1976, 1, 1256.

${ }^{23}$ Stephens, W P, et al, British Medical fournal, 1978, 1, 21.

${ }^{24}$ Tomlinson, I W, and Rosenthal, F D, British Medical fournal, 1977, 1, 1319.

${ }^{25}$ Naylor, W G, and Krikler, D, Postgraduate Medical fournal, 1974, 50, 441.

${ }^{26}$ Phear, D N, British Medical fournal, 1968, 2, 740.

27 Sandler, G, Clayton, G A, and Thornicroft, S G, British Medical fournal, 1968, 3, 224.

${ }^{28}$ Livesley, B, et al, British Medical fournal, 1973, 1, 375.

29 Nyberg, G, British Medical fournal, 1973, 3, 47.

30 Andreason, F, et al, European fournal of Cardiology, 1975, 2, 443.

31 Fagher, B, Svensson, S E, and Persson, S, Postgraduate Medical fournal, 1977, 53, 61 .

32 Vohra, J K, Drugs, 1977, 13, 219.

${ }^{33}$ New Therapy of Ischaemic Heart Disease, ed W Lochner, W Braasch, and G Kroneberg, p 12. Berlin, Springer-Verlag, 1975.

\section{Creutzfeldt-Jakob under control}

Dementias in general, and Creutzfeldt-Jakob disease in particular, have had an unexpected glut of publicity recently. ${ }^{12}$ In fact, the disease may not be so rare or its sufferers so innocuous to others as has been thought. Creutzfeldt-Jakob disease is one of a quartet of neurological disorders, the spongiform encephalopathies, with a common pathological picture. They have an inexorable course to death and are transmitted by filterable agents with enigmatic properties and a formidable stability when treated with physical and chemical agents. The other three are kuru (affecting the Fore tribe in New Guinea), scrapie of sheep, and transmissible mink encephalopathy. Of the four, Creutzfeldt-Jakob is the one of most clinical importance, because kuru is dying out, and the other two are believed not to infect man.

Creutzfeldt-Jakob disease is a presenile dementia ${ }^{3}$ progressing to coma and death and often characterised in the prodromal stage by myoclonus and a typical electroencephalogram. It has been transmitted by inoculation to various primates, and some strains of the agent are infective in cats and laboratory rodents. The laborious technique of animal inoculation has disclosed properties resembling those of the scrapie agent (though published work has sometimes failed to distinguish what has been actually discovered about Creutzfeldt-Jakob disease and what has been extrapolated to it from work with the mouse-adapted scrapie agent). For the time being the properties of the two agents may be assumed to be similar. The issue has become of practical importance because the disease appears to be more common in patients who have recently undergone neurological or ophthalmic surgery. ${ }^{4}$ There is also at least one well-authenticated case of transmission to the recipient of a corneal graft from a donor who had died of the disease ${ }^{5}$ and one account of transmission by stereotactic electroencephalographic electrodes. ${ }^{6}$

If the agent of this disease may be present in the body in an infective form even before overt clinical disease has developed, it raises all the problems created by the virus of hepatitis $B$, but in a more sinister form. There is no specific test for Creutzfeldt-Jakob disease, and there is no specific immunoglobulin for use after accidents. Above all, the agent is more resistant than most infective organisms to formalin, $70 \%$ alcohol, $\beta$-propriolactone, and boiling at $100^{\circ} \mathrm{C}$. Not surprisingly, there has been considerable anxiety, and those familiar with the agent have had many inquiries from clinicians and research workers about the possible hazards. On the other hand, Field" has dismissed the danger of contagion as "of very low order," and doctors and other medical care personnel do not, in fact, seem to have an unduly high incidence of the disease-a fact that gives grounds for reassurance.

Gajdusek $e t \mathrm{al}^{8}$ have recently published a paper specifically to answer the many inquiries about Creutzfeldt-Jakob disease. Their balanced account of the nature and degree of the hazards includes recommendations based on the known distribution of the agent within the body and other knowledge of this group of agents-for example, the fact that autoclaving for an hour or more at $121^{\circ} \mathrm{C}$ and $20 \mathrm{psi}$ inactivates the scrapie agent, and 5\% sodium hypochlorite, phenolic disinfectants, permanganate, and organic and alcoholic iodine solutions are all substantially active against it.

So far as risk of exposure is concerned, percutaneous inoculation of blood, tissue (especially brain), and cerebrospinal fluid should be taken seriously, whereas exposure to exhaled air or other body fluids is not a cause for anxiety. For noninvasive contamination of the skin, Gajdusek et al recommend thorough washing-but not scrubbing in case this abrades the skin. Patients with known disease are, of course, rare compared with carriers of hepatitis B, so that awareness is called for rather than alarm. Possibly some health care personnel may be specially at risk, but doctors less so perhaps than patients undergoing ophthalmic or brain surgery. Possibly, too, the Creutzfeldt-Jakob agent is yet another infective agent that has found life easier since the advent of various medical (and surgical) techniques. Be that as it may, there are good grounds 